\title{
Mothers.
}

\section{Spouses. (maybe)}

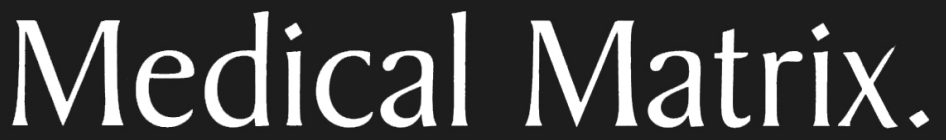

What do they have in common? You place your trust in them. When searching the Internet for credible medical information, you need a resource you can trust. The Lancet quotes that "Medical Matrix is the most comprehensive compendium of reliable medical information on the Internet."

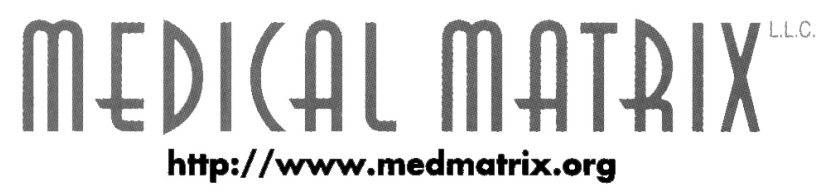

The largest, peer-reviewed directory to the medical Internet.

Free registration. 


\section{The Society for Healthcare Epidemiology of America}

\begin{tabular}{|c|c|c|c|}
\hline $\begin{array}{l}\text { President } \\
\text { PrESIDENT-Elect } \\
\text { VICE PRESIDENT } \\
\text { PAST PRESIDENT } \\
\text { SECRETARY } \\
\text { TREASURER }\end{array}$ & $\begin{array}{l}\text { William R. Jarvis, MD } \\
\text { Barry Farr, MD, MSc } \\
\text { Julie L. Gerberding, MD, MPH } \\
\text { Dale N. Gerding, MD } \\
\text { Larry J. Strausbaugh, MD } \\
\text { Rebecca Wurtz, MD }\end{array}$ & $\begin{array}{l}\text { ACADEMIC COUNCILOR } \\
\text { ACADEMIC COUNCILOR } \\
\text { PRACTICE COUNCILOR } \\
\text { PRACTICE COUNCILOR } \\
\text { lNTERNATONAL COUNCIOR }\end{array}$ & $\begin{array}{l}\text { Richard Platt, MD, MS } \\
\text { Trish Perl, MD, MSc } \\
\text { Farrin Manian, MD } \\
\text { Alan Tice, MD } \\
\text { Didier Pittet, MD, MS }\end{array}$ \\
\hline
\end{tabular}

\section{Draft HICPAC Guideline}

The HICPAC Draft Guideline for Prevention of Intravascular Catheter-Related Infections is available for public comment until October 22, 2001. The draft document was not published in the Federal Register.
The draft guideline, Federal Register Notice of Availability and Request for Comment, along with on-line request and comment pages, is available at the following web site: www.cdc.gov/ncidod/hip/ivguide.htm.

\section{Agency for Healthcare Research and Quality Issues Report on Patient Safety}

Public awareness of patient safety issues was heightened after national news coverage of victims of medical errors and a 1999 Institute of Medicine report, To Err Is Human: Building a Safer Health System. In response to this publication, the Quality Interagency Coordination Task Force released Doing What Counts for Patient Safety: Federal Actions to Reduce Medical Errors and Their Impact, listing over 100 action items for federal agencies to explore to reduce medical errors, thereby improving patient safety.

In July 2001, the Agency for Healthcare Research and Quality (AHRQ), the federal agency leading efforts to research and promote patient safety, issued the report Making Health Care Safer: A Critical Analysis of Patient Safety Practices. The report indicated that using an evidencebased approach can help identify practices that are likely to improve patient safety. It is the authors' hope that the report will serve as a template for future clinicians, researchers, and policy makers to extend and improve upon.

Although SHEA and the Association for Professionals in Infection Control and Epidemiology, Inc (APIC) are encouraged by the recognition of infection control and healthcare epidemiology as an important patient safety issue and by the report's acknowledgment of the value of infection control surveillance, prevention, and intervention programs in improving patient and healthcare worker safety and the quality of patient care, the organizations believe that the level of evaluation of existing data was insufficient and the recommendations often were not reflective of the most current and scientifically proven infection control and patient-safety practices.

Together, SHEA and APIC sent a formal response to Dr. John Eisenberg, Director, AHRQ, on August 2, 2001. You can read the SHEA and APIC response letter at www.shea-online.org/News.html. SHEA and APIC urge you to work with your patient-safety teams, quality and performance improvement colleagues, and administrative and policy personnel within your facilities to consider the many science-based and clinically proven patient safety practices in healthcare infection prevention and control before adopting the AHRQ report recommendations.

The full report can be located at www.ahcpr.gov/clinic/ptsafety, and a summary prepared by Dr. Salgado is located at SHEA's web site, www.shea-online.org.
In August 2000, Dr. Michael Decker stepped down as editor of $I C H E$, and the SHEA Publications Committee launched a search to fill the position, receiving applications from outstanding individuals. Dr. Barry Farr, University of VirginiaCharlottesville, was offered, and accepted, the position. Our Society is fortunate to have someone of Barry's respected scientific stature, extensive bibliography, and wide experience in healthcare epidemiology to accept this important position.

The new editor and his staff will face many challenges during the transition of the editorship from Nashville to Charlottesville. It is hoped that the Charlottesville office will open in October (for new submissions) and will be fully operational by early 2002 .

Thanks to Michael Decker, Susan Cantrell, and the rest of the Nashville ICHE staff for all their hard work. They will continue to play a critical role in the transition of the editorial office.

\section{Additional News Editor}

The SHEA Board of Directors is encouraging the "younger generation" of SHEA members to get more involved in the Society by volunteering for SHEA committees, such as the Membership Committee and the External Affairs Committee, as well as becoming involved with the $S H E A$ Newsletter and SHEA News page. The editors of this news page are very glad to welcome Cassandra Salgado to the news team. "Cassy" completed an Internal Medicine and Pediatrics residency at West Virginia University and is currently a second-year infectious diseases fellow at the University of Virginia. Her interests include the epidemiology of antimicrobial-resistant organisms and infection control. 

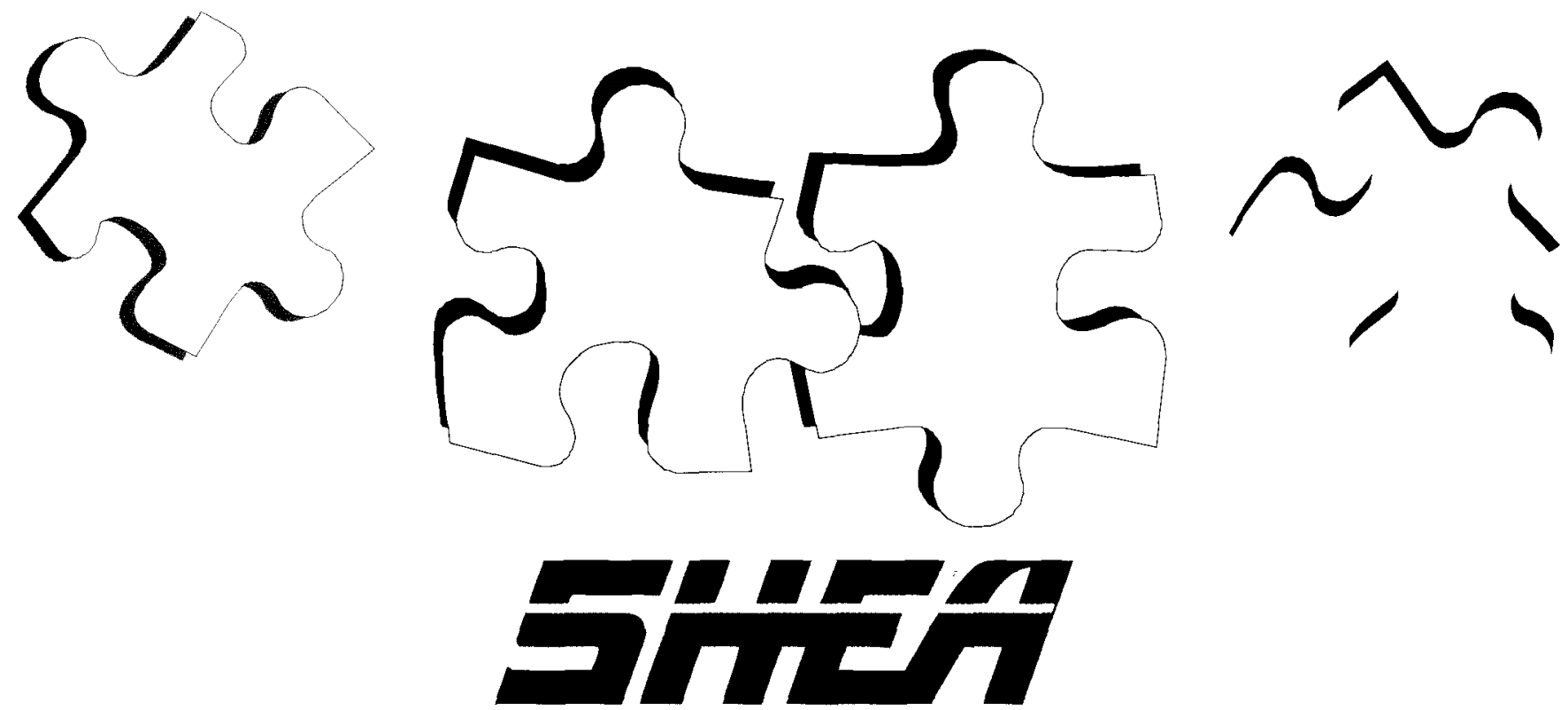

THE SOCIETY FOR HEALTHCARE EPIDEMIOLOGY OF AMERICA

\section{Where do you fit in SHEA?}

SHEA was established to advance the study and application of hospital epidemiology - both traditional infectious disease epidemiology and non-infectious disease epidemiology as they relate to patient care, health care worker safety, quality improvement and outcomes research in and out of the hospital setting.

SHEA's primary goal is to educate members and improve their ability to be infection control and quality assurance practitioners. This is accomplished through our journal, Infection Control and Hospital Epidemiology; a series of position papers by experts in the field; annual scientific meetings; training courses in hospital epidemiology; industry surveys; and a state grassroots legislative network.

SHEA has more than 1200 members from 29 countries that are active in SHEA and in infection control in their own countries.

We welcome all qualified individuals working or interested in healthcare epidemiology.
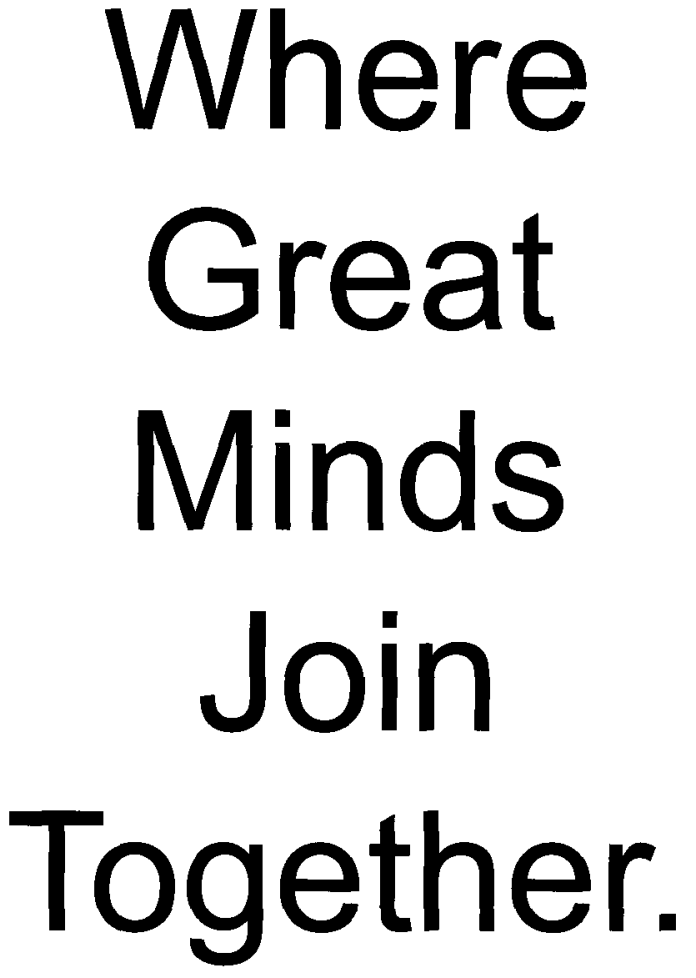

To inquire about becoming a member of SHEA, contact us today.

Phone: 856/423-0087

Fax: 856/423-3420

E-mail:sheahq@talley.com

Web site: www.shea-online.org

Mailing address: 19 Mantua Road, Mt. Royal, New Jersey 08061

\section{Smart membership benefits:}

As part of your SHEA membership, you will receive the following:

The society's official journalInfection Control and Hospital Epidemiology-at no charge. Non-members pay $\$ 109$ (U.S.) just for a subscription. That's the same price as annual membership dues in SHEA, which entitle you to yearlong benefits.

Access to the SHEA Web site, which includes position papers and data on salaries for healthcare epidemiologists and remuneration for part-time services in hospitals.

Reduced registration fees to annual scientific meetings and training courses.

Inclusion and access to the SHEA Membership Directory with more than 1200 member listings.

The opportunity to influence the field of healthcare epidemiology through participation on SHEA committees and boards. 


\section{Infection Control}

\section{BIOPATCH}

\section{Antimicrobial Dressing}

Nosocomial infections affect millions of patients annually and greatly increase treatment costs. BIOPATCH is the ONLY percutaneous device dressing that reduces nosocomial infection rates.

- Inhibits microbial population underneath by an average of 100 times as compared to skin under non-medicated patches

- Continually releases chlorhexidine gluconate for 7 days $^{1}$

- Broad-spectrum activity

- Absorbs eight times its own weight in fluid ${ }^{1}$

- One inch zone of inhibition

- Non-toxic, non-irritating ${ }^{1}$

\section{Indications For Use:}

- Central Venous Catheters (CVCs)

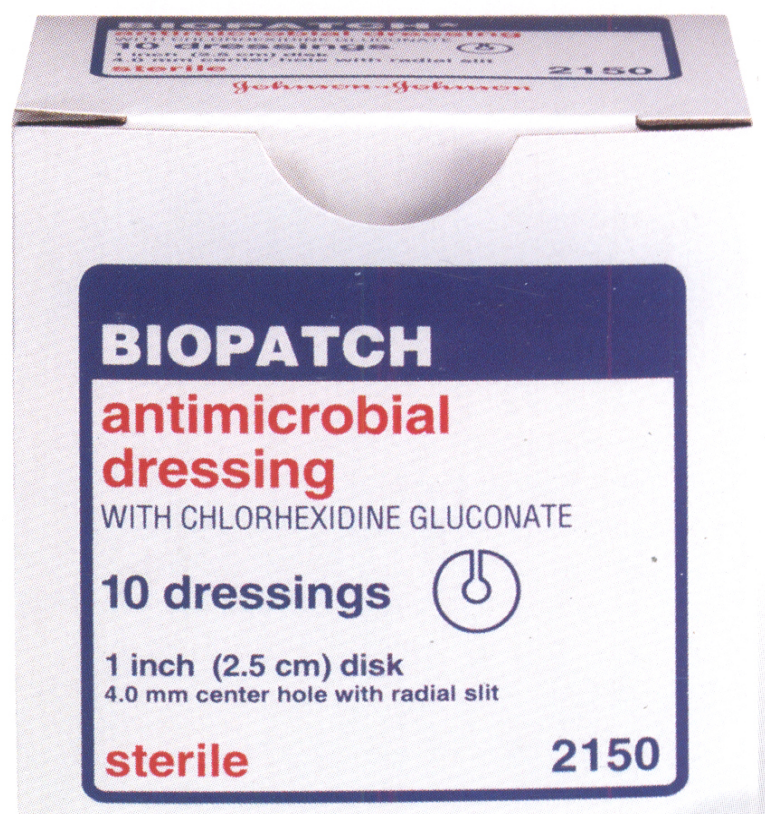

- Epidural analgesia catheters

- CAPD catheters

Gohnsonafohnson

- Orthopedic pins

For use with vascular and non-vascular percutaneous devices. Vascular devices include IV catheters, peripherally inserted central catheters, central venous lines, arterial catheters, dialysis catheters and others. Non-vascular percutaneous devices include external fixator pins, peritoneal dialysis catheters and epidural catheters.

'Shapiro JM, Bond EL, Garman JK. Use of chlorhexidine dressing to reduce microbial colonization of epidural catheter. Anesthesiology. 1990;73:625-631.

Capitalized product names are trademarks of ETHICON, INC.
Gohnson affohnson ADVANCED WOUND CARE a division of ETHICON, INC.

P.O. Box 151, Somerville, New Jersey 08876-0151 (c) ETHICON, INC. 2001 